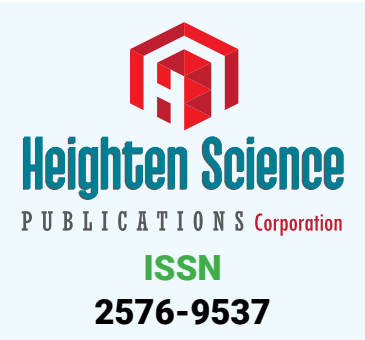

*Address for Correspondence: Marzia Cottini, MD, PhD Student, Department of Heart and Vessels, Cardiac Surgery Unit, "S. Camillo-Forlanini" Hospital, Circonvallazione Gianicolense 87, 00152, Rome, Italy, Tel: +39 347-3245331; Fax: +39-06-58704511; Email: marzia.cottini@gmail.com

Submitted: 05 August 2017

Approved: 25 August 2017

Published: 28 August 2017

Copyright: @ 2017 Cottini M. This is an open access article distributed under the Creative Commons Attribution License, which permits unrestricted use, distribution, and reproduction in any medium, provided the original work is properly cited.

\title{
The revolution of cardiac surgery evolution Running head: Cardiac surgery evolution
}

\author{
Marzia Cottini* \\ Department of Heart and Vessels, Cardiac Surgery Unit and Heart Transplantation Center, "S. Camillo- \\ Forlanini" Hospital, 00152 Rome, Italy
}

From the first case of primitive cardiac surgery (CS), treatment of stab wound of the heart (Dr. Daniel Hale Williams, 1893), to recent surgical procedures and device implantations for end-stage heart failure (HF), the CS has grown and emerged in the public health more and more [1].

The heart valve disease had interested immediately since the non-cardiopulmonary era because of the multitude of rheumatic patients and congenital valve disease. In the 1952, Hufnagel implanted the first valve in descending aorta and it was the sign of the first step of the CS evolution. New prosthesis and heart valve techniques were tested between 1970 and 2000 with optimal results in patients' quality of life and survival, at the same time of CPB evolution.

Whilst, the evolution of heart valve surgery had stimulated new devices, prosthesis and the development of minimally invasive surgery, this was partially diminished by the spreading of trans catheter valve implantation. In the 2002, Dr. Alain Crabbier described a non-surgical prosthetic valve implantation firstly: it was the revolution of CS evolution [2]. The transcatheter valve implantation has evolved and spread rapidly with multiple approaches femoral to apical, aortic, axillary and carotid, and many suitable and technological devices. The higher and higher risk patients, the needs to avoid surgical complications, the evolution of available devices and the fabrication of new technologies have increased the efforts to improve trans catheter valve implantation [3].

The recent article of Loyalka et al, described a special case of tricuspid valve in valve replacement with Sapien 3, an innovative and alternative therapeutic choice to a tricuspid valve degeneration [4]. Instead, Sawara et al [5], documented as trans catheter aortic valve implantation for a failing surgical bio prosthesis or native aortic valve regurgitation has become an alternative for patients at high risk for redo surgical aortic valve replacement or aortic regurgitation since now off-label: that was a reliable and significant results in the era of trans catheter valve implantations.

What would we attend from the future? In the most surgical centres, the trend were a significant decrease in patients undergoing to open-heart valve surgery compared to trans catheter valve implantation.

Maybe the new ongoing studies of lower and mild-risk patients undergone to transcatheter procedure would open either a deeper collaboration of the heart team and a new therapeutic perspectives in the public health with a shift to more minimally invasive procedures, less day of hospitalization and I don't see why not less costs for public health. 


\section{References}

1. Stephenson LW. History of cardiac surgery. Surgery: Basic Science and Clinical Evidence: Second Edition. 2008; 1471-1479. Ref.: https://goo.gl/1hw65d

2. Cribier A, Eltchaninoff $H$, Bash $A$, Borenstein $N$, Christophe $T$, et al. Percutaneous transcatheter implantation of an aortic valve prosthesis for calcific aortic stenosis: First human case description. Circulation. 2002; 106: 3006-3008. Ref.: https://goo.gl/ENfmga

3. Chamandi C, Puri R, Rodriguez-Gabella T, Rodés-Cabau J. Latest Generation TAVR Devices and Procedures. Can J Cardiol. 2017; 33: 1082-1090. Ref.: https://goo.gl/2ypbv4

4. Loyalka P. Transcatheter tricuspid valve-in valve replacement. 2017; 44: 209-213. Ref.: https://goo.gl/nyQx1K

5. Sawaya FJ, Deutsch MA, Seiffert M, Yoon SH, Codner P, et al. Safety and Efficacy of Transcatheter Aortic Valve Replacement in the Treatment of Pure Aortic Regurgitation in Native Valves and Failing Surgical Bioprostheses: Results From an International Registry Study. JACC Cardiovasc Interv. 2017; 10: 1048-1056. Ref.: https://goo.gl/PR3hyv 